\title{
Multiple myeloma treated with single agent dexamethasone
}

\author{
Acharya SC ${ }^{1}$, Karn $\mathrm{A}^{2}$, Acharya $\mathrm{B}^{3}$, Paudel BD
}

${ }^{1}$ Sandhya Chapagain Acharya, Assistant Professor; ${ }^{2}$ Ambuj Karn, Assistant Professor; ${ }^{3}$ Bibek Acharya, Associate Professor; ${ }^{4}$ Bishnu D. Paudel, Professor; Department of Clinical Oncology, National Academy of Medical Sciences (NAMS), Bir Hospital, Kathmandu, Nepal

\begin{abstract}
Multiple myeloma is less frequently diagnosed in our part of the world. As per the hospital based cancer registry of Nepal, it accounts for $0.4 \%$ of all cancer cases diagnosed annually'. Usually they present with symptoms of chronic renal failure which is part of CRAB: elevated calcium (C), renal failure (R), anemia (A) and bone lesions (B). The symptoms and signs vary greatly as many organs can be affected by myeloma. Furthermore, the incidence is high in older age group with co morbidities demanding the patient tailored treatment. Here, we present a case of multiple myeloma which was treated with single agent dexamethasone. On initial evaluation patient had stage III disease with features of cord compression, so was started with immediate radiation therapy to the cervical and lumbar vertebrae followed by single agent dexamethasone as he denied further cytotoxic treatment. The patient is on regular follow up and in remission after six years of treatment. We are in the era where there is armor of chemotherapeutic agents along with bone marrow transplantation for the treatment of multiple myeloma. This case may represent an example and single agent dexamethasone can be an option for the treatment of the patient who is in poor general condition to receive the cytotoxic chemotherapy or denies to such therapy but it should be a choice only to a selected subgroup of patient population.
\end{abstract}

Key words: Chemotherapy, Dexamethasone, Multiple Myeloma

\section{INTRODUCTION}

ultiple myeloma (MM) is less frequently diagnosed I in our context. The most common clinical presentation we encounter is with renal involvement and/or with skeletal metastasis. Most of the cases are seen in an older age group with poor performance status and associated comorbidities hence patient-tailored treatment is another challenge while treating these patients ensuring adequate supportive treatment and at the same time minimizing the treatment related toxicity. Here, we present a case of MM which was treated with single agent dexamethasone.

\section{CASE REPORT}

A 60 year gentleman presented to our hospital in 2009 with the history of backache for eight months duration. He was initially evaluated outside hospital, diagnosed as MM and planned for chemotherapy with Vincristine, Doxorubicin, and Dexamethasone (VAD) regimen. He was referred to our hospital with acute renal failure

Address for correspondence

Dr. Sandhya C. Acharya

Assistant Professor

Department of Clinical Oncology, NAMS, Bir Hospital

E-mail: sandhyachap@gmail.com for dialysis after first cycle of chemotherapy which may have been precipitated because of pre existing CRAB. After his acute kidney injury subsided, he was referred to our department for further management. At presentation, patient had vertebral metastasis $\mathrm{C} 6$ to $\mathrm{C} 7$ and D10 to D12 with tingling sensation both lower limbs. He was then evaluated and staged as Stage III (DurieSalmon Criteria), $\beta-2$ microglobulin was $4268 \mathrm{ng} / \mathrm{dl}$ with evidence of " $\mathrm{M}$ " band on plasma electrophoresis, along with bone marrow plasma cell of $90 \%$. Tumor board meeting decided for immediate radiation therapy (RT) to the vertebrae in view of impending cord compression. Single agent Dexamethasone $40 \mathrm{mg} /$ day on Days D1 to $D 4, D 9$ to D12, D17 to D20 every four weeks was planned as the patient was reluctant for chemotherapy due to previous complication of chemotherapy and his poor performance status. Thus, dexamethasone was started along with radiation therapy following which four weekly Zoledronic acid was added. At the completion of RT patient was able to walk by himself. Then he was kept on regular dexamethasone and Zoledronic acid. After completion of three cycle of dexamethasone, the investigations were repeated and recorded as: $\beta-2$ microglobulin $2433 \mathrm{ng} / \mathrm{dl}$, absent of " $M$ " band in serum electrophoresis. The same treatment was continued. He 
could complete six cycles of dexamethasone which was then stopped as he developed herpes zoster infection. After being treated for herpes zoster, he was again started with Zoledronic acid four weekly which he received for one and half year duration. He was then kept on three monthly follow-up during which $\beta-2$ microglobulin further decreased to $1746 \mathrm{ng} / \mathrm{dl}$, and bone marrow biopsy showed normal marrow study. The patient is now on regular 3-4 monthly follow for the last six years with stable clinical, radiological and biochemical parameters with latest $\beta-2$ microglobulin level of $1227 \mathrm{ng} / \mathrm{dl}$ and normal marrow cellularity.

\section{DISCUSSION}

MM arises from malignant transformation of a latestage $B$ cell. The incidence rises with advancing age. The median age ranging from 60 to 66 years $^{2}$. MM has a wide clinical spectrum, ranging from the preclinical condition of monoclonal gammopathy of unknown significance (MGUS) to the most aggressive form, plasma cell leukemia. Whatever the clinical presentation, in all cases plasma cell clone exists and the monoclonal protein secreted by these cell play major role in end organ damage $^{3}$.

It is a disease of old age and clinical approach to older patients with myeloma has to be modified to take into account comorbidities and the likelihood of higher treatment-related toxicity. Individualization of management and adequate supportive therapy are important to obtain the best response while minimizing adverse effects. As mentioned earlier, the patient had CRAB and spinal cord compression at presentation ${ }^{4}$.

The reported case was discussed in tumor board and was planned for emergency radiation therapy (RT) to the vertebrae. Patient received standard palliative RT used for cord compression in MM, $30 \mathrm{~Gy} / 10$ Fractions $^{5}$.

\section{REFERENCES}

1. National Cancer Registry Programme, Report of Hospital Based National cancer Registry; B.P. Koirala Memorial Cancer Hospital: 2012.

2. Perez CA, Brady LW, Halperin EC, Wazer DE: In Principles and Practice of Radiation Oncology, Sixth Edition, Lippincot William and Wilkins; 2013, 15991600.

3. Hideshima $\mathrm{T}$, Bergsagel $\mathrm{PL}$, Kuehl WM, et al. Advances in biology of Multiple myeloma: clinical applications. Blood 2004:104(3);607-618
Patient was then started with single agent dexamethasone at a dose of $40 \mathrm{mg}$ orally for the four consecutive days repeated after four days off, which is one of the important regimens since mid-1980s. This has response rates of $60 \%$ to $70 \%$ in previously untreated patients and appeared to be as high as those in patients treated with VAD regimen ${ }^{6,7}$. As shown in a prospective trial which randomly assigned 488 patients older than 65 years to receive treatment in four different groups: dexamethasone alone, melphalan plus dexamethasone, dexamethasone plus Interferon-alpha, and melphalan plus prednisone (MP). With a median follow-up of 7.1 years, no difference was observed in overall survival (OS) in four treatment group?

As the patient responded wonderfully to the treatment, zoledronic acid was continued for one and half year. Administration of zoledronic acid significantly reduces the skeletal related events along with improvement of the median overall survival ${ }^{9,10,11}$.

We are in the era where there is armor of chemotherapeutic agents to treat myeloma along with bone marrow transplantation. The case reported here might not be in accordance with the current practice but could be an option to help achieve remission with good quality of life and significantly less morbidity and chemotherapeutic related toxicity in the situation demanding tailored treatment.

\section{CONCLUSION}

We reported this case of successful treatment with single agent dexamethasone and patient on remission for the last six years, which might be extrapolated in other patient population of MM whose performance status is poor and reluctant to receive chemotherapy due to fear of its toxicity. So we conclude that single agent dexamethasone still can be a choice for selected subgroup of patients who cannot tolerate or afford other treatment regimens.

4. Mehta J, CavoM, Singhal S: How I treat elderly patients with myeloma. Blood 2010:116(13)

5. Rades D, Hoskin PJ, Stalpers LJ, et al.: Shortcourse radiotherapy is not optimal for spinal cord compression due to myeloma. Int J Radiat Oncol Biol Phys 2006: 64(5);1452-7.

6. Alexanian R, Dimopoulos MA, Delasalle $K$, et al.: Primary dexamethasone treatment of multiple myeloma. Blood 1992: 80(4);887-90.

7. Kumar S, Lacy $M Q$, Dispenzieri $A$, et al.: Single agent dexamethasone for pre-stem cell transplant 
induction therapy for multiple myeloma. Bone Marrow Transplant 2004: 34(6);485-90, 2004.

8. Facon T, Mary JY, Pégourie B, et al.: Dexamethasonebased regimens versus melphalan-prednisone for elderly multiple myeloma patients ineligible for highdose therapy. Blood 2006: 107(4);1292-8.

9. Morgan GJ, Child JA, Gregory WM, et al.: Effects of zoledronic acid versus clodronic acid on skeletal morbidity in patients with newly diagnosed multiple myeloma (MRC Myeloma IX): secondary outcomes from a randomised controlled trial. Lancet Oncol 2011: 12(8);743-52.

10. Morgan GJ, Davies FE, Gregory WM, et al.: Effects of induction and maintenance plus long-term bisphosphonates on bone disease in patients with multiple myeloma: the Medical Research Council Myeloma IX Trial. Blood 2012: 119(23);5374-83.

11. Mhaskar R, Redzepovic J, Wheatley $\mathrm{K}$, et al.: Bisphosphonates in multiple myeloma: a network meta-analysis. Cochrane Database Syst Rev 2012: 5;CD003188. 